\title{
Incidencia de la Ley 38/1998, de 5 de noviembre, de Ordenación de la Edificación en el ámbito de la Administración local
}

\author{
María Nieves de la Serna Bilbao \\ Profesora Titular de Universidad \\ Universidad Carlos III de Madrid
}

\begin{abstract}
SUMARIO: I. PLANTEAMIENTO DE LA CUESTIÓN. II COMPETENCIA NORMATIVA DE LOS MUNICIPIOS RELACIONADA CON LA EDIFICACIÓN. III. LA COMPETENCIA INSTRUMENTAL DIRIGIDA A VERIFICAR EL CUMPLIMIENTO DE DETERMINADAS OBLIGACIONES IMPUESTAS POR LA LOE A OTROS SUJETOS. A) Régimen general. B) Sujeto habilitado para gestionar las licencias de obra. C) Suficiencia del título para construir; el derecho de propiedad y otros derechos a construir en finca ajena. a) Derecho de propiedad. b) Derecho de superficie y otros derechos constituidos sobre finca ajena. c). Derecho de vuelo. d). Permuta de solar por piso futuro. D) El proyecto de edificación. a) Control urbanístico. b) Control de cumplimiento de normativa técnica. c) Confección por profesional competente d) Contar con visado profesional. E) El mantenimiento del edificio.
\end{abstract}

\section{PLANTEAMIENTO DE LA CUESTIÓN}

Como es conocido, la actividad edificatoria, en general, de la construcción, ha tenido tradicionalmente en el conjunto de la economía de nuestro país una importancia que no es posible desconocer; hasta el punto de que dicho sector constituye una de las principales variables que son tenidas en cuenta para determinar la marcha de la situación económica. Es preciso destacar, sin embargo, que, a pesar de su importancia, dicho sector no se ha visto acompañado de una regulación acorde que abordase y diera respuesta a los múltiples problemas planteados. En efecto, se debe señalar que en el proceso de formación de la normativa reguladora del sector de la edificación han incidido otros sectores, - como el laboral, el sanitario, la vivienda o el urbanismo- - cada uno desde su propia perspectiva individual, al margen de todo intento, siquiera, de articulación desde un plano superior o de conjunto. $\mathrm{Y}$ tal realidad, determinada tanto por la amplitud inherente al ámbito material de nuestro objeto de estudio (comprensivo de materias relacionadas con la seguridad e higiene en el trabajo; los requisitos de los proyectos constructivos; la determinación de las características de los materiales de la construcción; la delimitación del ámbito de actividad de los sujetos intervinientes en el proceso edificatorio, la concreción del régimen de responsabilidad, etc.), como por la aparición de nuevas cir- 
cunstancias dignas de consideración (nuevos sujetos intervinientes que ha dado lugar a un proceso de especialización en las tareas a desarrollar o, la aparición y desarrollo de nuevas técnicas de construcción, etc...), ha producido, no sólo una dispersión normativa importantísima, con múltiples disposiciones fragmentarias, en ocasiones, incluso contradictorias entre sí y desfasadas por el mero transcurso del tiempo sino, lo que resulta más grave, la existencia de serias lagunas e insuficiencias legales. Esta situación resultaba especialmente evidente en relación con la responsabilidad civil de los agentes intervinientes en el proceso edificatorio, cuestión regulada por el artículo 1591 del Código Civil que tuvo que ser interpretado por la Jurisprudencia del Tribunal Supremo desde una perspectiva amplia con el fin de dar cabida a otros sujetos (como promotor, proyectistas, director de la ejecución de la obra, etc...) diferentes a los arquitectos y contratistas, sin los cuales no es posible comprender, hoy en día, la actividad edificatoria.

Sobre esta situación incidían, a su vez, otras circunstancias que venían a agravar aún más la situación brevemente descrita. En primer lugar, los conflictos surgidos en relación con la determinación normativa de las competencias profesionales de los distintos técnicos facultativos intervinientes en el proceso de edificación - participación que se debe realizar siempre de conformidad con las normas que regulan los correspondientes cometidos profesionales y delimitan los campos de cada sujeto competente-, agravados como consecuencia de la progresiva diversificación de las profesiones técnicas y de la complejidad del proceso edificatorio sin que se hubiera procedido a modificar la normativa vigente. En segundo término, es preciso destacar que como consecuencia de la progresiva materialización de las competencias asumidas en la materia por parte de las Comunidades Autónomas diferentes iniciativas legislativas empiezan a ver la luz.

Es esta situación la que se intenta afrontar con la promulgación de la Ley 38/1999, de 5 de noviembre, de Ordenación de la Edificación —en adelante, $\mathrm{LOE}$ - , que representa un primer intento de reconducir a cierta unidad el sistema legal ${ }^{1}$, consolidando la edificación como una materia

\footnotetext{
${ }^{1}$ La necesidad de contar con una regulación homogénea no era ignorada. Lo cierto es que la LOE fue precedida de varias iniciativas legislativas que nunca han visto la luz. Entre ellas, se pueden citar las iniciadas por el Ministerio de Obras Públicas y de Vivienda a consecuencia de la elaboración del denominado «Libro Blanco de la edificación» en 1978, de la que surgió, entre otros, el proyecto legislativo de 1980, elaborado sobre la base de un estudio relativo a la viabilidad de la Ley General de edificación realizado por el propio Ministerio que no culmina ni tan siquiera en el Congreso. En 1992, se retoma el tema y se elaboró un documento base — difundido entre los distintos sujetos afectados con el fin de que realicen las observaciones oportunas-, a partir del cual
} 
jurídica con sustantividad propia, concretando el concepto de edificación, definiendo paralelamente los requisitos a los que se debe ajustar el desarrollo de la misma en relación, claro está, con los diferentes intereses de todas las partes intervinientes en el proceso edificatorio y, finalmente, actualizando el estatuto de los sujetos partícipes en la misma. No obstante, no se puede dejar de mencionar que en la actualidad la actividad edificatoria sigue siendo objeto de regulación por un complejo diverso de normativas jurídico-públicas y jurídico-privadas, con sustantividad propia (desde el punto de vista del reparto territorial de la competencia legislativa).

Pues bien, el estudio de dicho texto legal se realiza, generalmente, desde una metodología que podríamos considerar lineal, en el sentido que analiza secuencialmente los diferentes aspectos regulados por el mismo. Esta posición, si bien ofrece una visión plena de la LOE, no tiene en cuenta, sin embargo, su posible incidencia en otros sujetos públicos que, como la Administración Local, juegan, en cualquier caso, un papel importante en el ámbito de la edificación en tanto que el legislador les atribuye - al margen de su competencia normativa verificada a través de las Ordenanzas Municipales de Edificación- determinadas obligaciones que podemos considerar como instrumentales dado que están dirigidas a verificar el cumplimiento de determinadas obligaciones directas o principales, impuestas a ciertos agentes de la edificación. En efecto, a ésta le incumbe dicho papel desde dos perspectivas:

a) Objetiva: por afectar a determinadas exigencias o requisitos que deben tener los inmuebles objeto de edificación. Subjetiva: se trata de exigencias de distinta índole que se imponen a determinados agentes edificadores y cuya verificación de cumplimiento se impone al Ayuntamiento correspondiente. Se trata fundamentalmente de dos cuestiones:

a') Suficiencia del título legitimador de la edificación.

b') Capacidad de determinados sujetos para intervenir en el proceso edificatorio y determinación del ámbito de licita intervención.

Es el análisis de estas cuestiones el objeto de este trabajo.

se confeccionó un proyecto de Ley publicado en el Boletín Oficial de las Cortes Generales - con fecha 9 de enero de 1996, Congreso de los Diputados, Serie A, número 146-1, 121/000130-. Finalmente, en 1998, se retomó el asunto y se elaboraron varios anteproyectos que, previa consulta a los distintos sujetos afectados por la regulación, dio lugar a la Ley 38/1999, de 5 de noviembre, de Ordenación de la Edificación (en adelante, LOE). 


\section{COMPETENCIA NORMATIVA DE LOS MUNICIPIOS RELACIONADA CON LA EDIFICACIÓN}

Como es sabido, las entidades locales son instancias territoriales dotadas de autonomía, constitucionalmente garantizada para la gestión de sus respectivos intereses (artículos 137 y 140 de la Constitución); gestión que comprende, desde la propia Constitución y, como parte misma de dicha garantía institucional, la potestad normativa que resulta, de este modo, originaria, si bien, circunscrita al marco determinado según los casos por el legislador estatal y por el autonómico que, en cualquier caso, debe ser respetuosa con dicha garantía. Desde esta perspectiva, es posible afirmar - siguiendo en este punto a PAREJo Alfonso ${ }^{2}$ - que las normas locales tienen su propia especificidad ya que siendo el resultado de una potestad normativa propia se produce en el seno de un ordenamiento territorial autónomo, articulado con los ordenamientos superiores a través de la ley, de suerte que dichas normas locales no son desarrollo de textos locales, sino traducción de opciones locales que deben respetar los límites externos determinados por aquellos ordenamientos.

Pues bien, hay que recordar, en este sentido, la obligación que recae sobre el legislador sectorial de asegurar a los municipios tanto su derecho a intervenir en cuantos asuntos afecten directamente al círculo de sus intereses, atribuyéndoles las competencias que procedan en atención a las características de la actividad pública de que se trate y a la respectiva capacidad de gestión de la entidad local y, entre otras, en materia de urbanismo, de protección civil, de prevención y de extinción de incendios; de promoción y de gestión de viviendas; de patrimonio histórico artístico; de protección del medio ambiente; de defensa de usuarios y de consumidores; de protección de la salud pública; de instalaciones culturales y deportivos — artículo 25, apartados c), d), e), f), g), h), y m) de la LrBRL ${ }^{3}$, cuestiones, todas ellas, atinentes a diferen-

\footnotetext{
${ }^{2}$ Sobre esta cuestión, véase L. PARejo Alfonso, Garantía institucional y Comunidades autónomas; Ed. IEAL; Madrid, 1981, «La autonomía local en la Constitución» en Tratado de Derecho Municipal; Edit. Civitas; Madrid, 1988; pp. 17 y ss., y La potestad normativa de los entes locales; Edit. Marcial Pons; Madrid, 1998.

${ }^{3}$ Según dispone el artículo citado «Para la efectividad de la autonomía garantizada constitucionalmente a las entidades locales, la legislación del Estado y la de las Comunidades Autónomas, reguladora de los distintos sectores de actividad pública, según la distribución constitucional de competencias, deberá asegurar a los municipios, las Provincias y las Islas, su derecho a intervenir en cuantos asuntos afecten directamente al círculo de sus intereses, atribuyéndoles las competencias que procedan en atención a las características de la actividad pública de que se trate y a la capacidad de gestión de la entidad local de conformidad con los principios de descentralización y máxima proximidad de la gestión administrativa a los ciudadanos».
} 
tes aspectos relacionados, de una u otra manera, con el sector de la edificación-.

En relación con este orden de ideas, es preciso destacar, igualmente, el reconocimiento competencial que, en beneficio de la Administración local, realizan tanto el legislador estatal como el autonómico en materia de procedimientos administrativos y de normas edificatorias. En el primer caso, se tata de Ordenanzas que concretan ciertos procedimientos administrativos, como puede ser el de otorgamiento de las licencias de obra y de usos. Estos procedimientos deben respetar tanto la Ley de cabecera estatal, es decir, la Ley 30/1992, de 26 de noviembre, de régimen jurídico de las Administraciones Públicas y procedimiento administrativo común (en adelante, RJAP y PAC), emitida en virtud del artículo 149.1.18 CE y reguladora, como es sabido, del procedimiento común de las Administraciones Públicas que concreta las instituciones comunes a la totalidad de las actuaciones derivadas del desarrollo de la actividad formalizada de cualquiera de las Administraciones (art. 2.1 y 2 de dicho texto legal), como la legislación autonómica que, en virtud de las competencias materiales asumidas, puede regular no sólo los aspectos organizativos de la materia de que se trate, sino también los procedimentales debiendo dejar, en este caso, el correspondiente ámbito a la Administración Local. De esta forma, coexisten una pluralidad de ordenaciones procedimentales, es decir, de procedimientos específicos y ello dentro de cualesquiera de los ordenamientos territoriales del Estado: general, autonómicos y locales.

Las Ordenanzas de la edificación, por su parte, vienen siendo definidas explícitamente por la normativa urbanística autonómica por su ámbito material de aplicación, como aquellas que regulan «...los aspectos morfológicos y ornamentales de las construcciones y, en general, aquellas condiciones de las obras de edificación que no sean definitorias de la edificabilidad o del destino del suelo. También pueden regular, en términos compatibles con el planteamiento, las actividades susceptibles de autorización en cada inmueble. Y de acuerdo con la posición expuesta en estas páginas «... deberán ser conforme con las disposiciones estatales o autonómicas relativas a la seguridad, salubridad, habitabilidad y calidad de las construcciones y en ningún caso menoscabarán las medidas establecidas para la protección del medio ambiente o de los medios catalogados de interés cultural o histórico» ${ }^{4}$. En consecuencia, no pueden regular aspec-

\footnotetext{
${ }^{4}$ Véase en este sentido, la Ley 6/1994, de 15 de noviembre, reguladora de la actividad urbanística de la Comunidad Valenciana, respecto de las Ordenanzas Municipales de policía de la edificación (artículo 15); la Ley 2/1998, de 4 de junio, de Ordenación del Territorio y de la Actividad Urbanística, de Castilla-La Mancha (artículo 16); la Ley 5/1999, de 25 de marzo, urbanística de
} 
tos estructurales de la edificación (competencia propia del legislador estatal asumida en la LOE), ni tampoco del destino del suelo (competencia estatal o autonómica).

Asimismo, las Ordenanzas citadas pueden desarrollar la normativa técnica comprensiva de los aspectos relacionados con la habitabilidad, seguridad, etc., siempre claro está respetando la normativa que al respecto exista a nivel estatal (básicamente, en el artículo 3 de la LOE que se recogerá en el futuro Código Técnico de la Edificación) y la autonómica (de acuerdo con sus competencias, relacionada principalmente, con la materia de vivienda y que complete el futuro Código Técnico de la Edificación —art. 3.2 de la LOE-).

En todo caso, es preciso destacar que la atribución a las Corporaciones locales de competencias en materia de edificación tiene la ventaja que permite complementar desde la perspectiva local, las actuaciones estatales y autonómicas en la materia y dar satisfacción, de este modo, a objetivos que puedan ser definidos por dicha Corporación de forma más precisa que las instancias territoriales superiores.

\section{LA COMPETENCIA INSTRUMENTAL DIRIGIDA A VERIFICAR EL CUMPLIMIENTO DE DETERMINADAS OBLIGACIONES IMPUESTAS POR LA LOE A OTROS SUJETOS}

\section{A) Régimen general}

A la Administración Local le corresponde verificar el cumplimiento de los requisitos establecidos por la LOE cuando autoriza la realización de actos de edificación. En efecto, como es sabido, de acuerdo con lo dispuesto por nuestro ordenamiento jurídico toda decisión relativa a la transformación, el aprovechamiento y la utilización del suelo que exceda del mero uso o disfrute individual conforme a la naturaleza propia de dicho bien se traslada desde la pura conveniencia o arbitrio individual del propietario a la Administración pública. Se logra, de este modo, articular los

\footnotetext{
Aragón (art. 64), en el cual si bien el contenido es el mismo que las otras la denomina Ordenanzas Urbanística; el Decreto Legislativo 1/2000, de 8 de mayo, de Ordenación del Territorio y espacios naturales de Canarias (art. 40), la Ley 2/2001, de 25 de junio, de Ordenación territorial y Régimen urbanístico (art. 62) (en este caso las denomina también Ordenanza Urbanística pero su contenido no es igual aunque comprende parte de su ámbito); la Ley 9/2001, de 17 de julio, de suelo de Madrid (art. 32); la Ley 15/2001, de 14 de diciembre, de suelo y ordenación territorial de Extremadura (art. 85); La Ley 3/2002, de 19 de abril, de urbanismo de Asturias, art. 61.
} 
diferentes intereses públicos-privados en presencia a la hora de utilizar el suelo, dirigiéndose la actividad de la Administración a verificar si aquellos actos de aprovechamiento del suelo se producen de conformidad o no con las determinaciones fijadas por la legalidad vigente. Pues bien, la herramienta utilizada tradicionalmente con tal fin ha sido la licencia. Mediante su empleo se persigue controlar, con carácter previo, la conformidad de las actividades urbanísticas y edificatorias que se pretenden desarrollar con las normas aplicables en cada caso. La licencia se configura así, tanto por la legislación básica estatal, ya sea la reguladora del Régimen Local [arts. 21.1.11) y 84.1 de la LrBRL], ya sea la de naturaleza urbanística (arts, 242.1 y 243.1 TRLS 92), como por la legislación autonómica, como un requisito necesario para el legítimo ejercicio de todos aquellos actos de edificación y uso del suelo (incluido, el subsuelo) previstos por Ley ${ }^{5}$. De esta forma, la fase de construcción o edificación de las parcelas o solares, es decir, de las unidades finales de aprovechamiento urbano (y sus equivalentes de ampliación, reforma o modificación, así como los de derribo de edificios ya existentes) y, por supuesto, el uso o la utilización posterior de los edificios o instalaciones en tanto subsistan, no puede dar comienzo, legítimamente, hasta que la licencia municipal y la autorización de que se trate estén otorgadas. Como reiteradamente tiene reconocido el Tribunal Supremo «...la falta de licencia municipal no queda suplida por autorizaciones de diversa naturaleza ni por el pago de los correspondientes impuestos, ni subsanada por la mera tolerancia administrativa» ${ }^{6}$. En definitiva, el Derecho urbanístico parte de la consideración de que para la realización legítima de obras o usos del suelo es preciso contar ex ante con las correspondientes autorizaciones y licencias urbanísticas procedentes. Pues bien, es preciso destacar que la LOE reitera dicha exigencia, disponiendo el artículo 5 del citado texto legal que < <la construcción de edificios, la realización de las obras que en ellos se ejecuten y su ocupación precisará las preceptivas licencias y demás autorizaciones administrativas procedentes, de conformidad con la normativa aplicable >>. La importancia de tal exigencia deriva en este caso, sin embargo, de la circunstancia de que es justamente la licencia el instrumento que va a permitir desarrollar el control subjetivo relativo tanto al título legitimador de la voluntad de construir, como la capacidad de lícita intervención en el proceso edificatorio de ciertos sujetos. En todo caso, debe quedar claro que con la licencia se incide sobre el ejercicio del derecho a la edificación o uso del suelo, no sobre el contenido del derecho en sí.

\footnotetext{
${ }^{5}$ Es preciso destacar que dado que la preceptividad de la misma es en $<<$ todos los actos de edificación y uso del suelo〉> las exclusiones son muy limitadas.

${ }^{6}$ STS de 14 de junio de 1989.
} 
En la actualidad, es preciso destacar que las exigencias de control de la Administración local a la hora de otorgar las licencias de edificación son diferentes según que el tipo de edificación que se pretenda desarrollar se encuentre sujeto o no a la LOE. En el primer supuesto el Ayuntamiento deberá verificar el cumplimiento de las exigencias impuestas por dicho texto legal; en las restantes edificaciones el Municipio deberá controlar las concretadas por la legislación aplicable en cada caso.

La LOE resulta de aplicación al proceso edificatorio definido como «... la acción y el resultado de construir un edificio de carácter permanente, público o privado...», comprendiendo también las «...instalaciones fijos y el equipamiento propio, así como los elementos de urbanización que permanezcan adscritos al edificio» (art. 2, aps. 1 y 3). Concreta como edificaciones comprendidas dentro de aquel proceso:

a) Las obras de edificación de nueva construcción, excepto las construcciones de escasa entidad constructiva y sencillez técnica que no tengan carácter residencial —eventual o permanente- ni uso público y se desarrolle en una sola planta.

b) Las obras de ampliación, modificación, reforma, o rehabilitación que alteren la configuración arquitectónica de los edificios o tengan por objeto cambiar los usos característicos del edificio. Se entiende que se produce una «alteración de la configuración arquitectónica», cuando aquellas obras tengan carácter de intervención total o parciales que produzcan una variación esencial de la composición general exterior, la volumetría, o el conjunto del sistema estructural o tengan por objeto cambiar los usos característicos del edificio».

c) Las obras desarrolladas en edificaciones catalogadas o que dispongan de algún tipo de protección de carácter ambiental o histórico-artístico, regulada a través de norma legal o documento urbanístico. Se incluyen dentro de este grupo todas las de carácter de intervención total así como las parciales, siempre que en este último supuesto afecte a los elementos o partes objeto de protección.

Quedan fuera del ámbito de la LOE, por tanto, las obras menores, obras de simple reparación, decoración u ornamentación que en ningún caso comporten la modificación de la estructura del edificio y las que no alteren la configuración arquitectónica o cambien los usos del edificio. 
Teniendo en cuenta los requisitos establecidos por la LOE el Municipio en el procedimiento de otorgamiento de la licencia de obra debe tener en cuenta:

\section{B) Sujeto habilitado para gestionar las licencias de obra}

De conformidad con el artículo 9.2.c) LOE, el procedimiento administrativo de solicitud de licencia ha de ser promovido necesariamente por el promotor definido legalmente como «cualquier persona, física o jurídica, pública o privada, que, individual o colectivamente, decide, impulsa, programa y financia, con recursos propios o ajenos, las obras de edificación para sí o para su posterior enajenación, entrega o cesión a terceros bajo cualquier título» ${ }^{7}$, a quien corresponde «Gestionar y obtener las preceptivas licencias y autorizaciones administrativas, así como suscribir el acta de recepción de la obra». Es preciso señalar que esta obligación no implica, necesariamente, que deba ser realizada por el promotor personalmente. Antes al contrario, éste puede utilizar la figura de la representación y contratar para la realización de dichos trámites administrativos con gestoras o con personas que realicen, en su nombre, la citada tramitación. A la Administración le basta con comprobar que el solicitante cumple el requisito de ostentar la condición de interesado (ya sea porque es propietario, ya sea porque ostenta un título suficiente, etc.). En todo caso, es importante destacar que la LOE presume que quien realiza estas gestiones es el promotor, pues este sujeto es el que decide, impulsa, programa y financia la edificación (art. 9.1) y con tal finalidad promueve el proceso administrativo de solicitud de licencia. Esta identificación es muy importante pues el sujeto que se demuestre que desarrolló tales funciones es a quien se le aplicará el sistema de responsabilidad (solidaria) establecido en el citado texto legal (art. $17 \mathrm{LOE})$.

Como es sabido, la iniciación del procedimiento administrativo de solicitud de licencia al ser rogado, precisa, necesariamente, la formulación y presentación de la correspondiente solicitud en debida forma, esto es, cumpliendo los requisitos generales recogidos en la LRJAP y PAC — ar-

\footnotetext{
${ }^{7}$ Se diferencia este sujeto, tanto del constructor (definido en el art. $11 \mathrm{LOE}$ ), como del vendedor, que está excluido del ámbito de aplicación de la LOE (art. 17.6). La jurisprudencia del Tribunal Supremo (SSTS 15-10-96 o 26-06-97, entre muchas otras) identifica al vendedor con la función de mero gestor por realizar labores de mera intermediación (búsqueda de personas interesadas en la adquisición de una vivienda para integrarlas en una Comunidad de propietarios con la obligación de participar en los costes de construcción) y, en tal sentido, perciben honorario. Por el contrario, el promotor, se cualifica por realizar las funciones de «decide, impulsa, programa y financia» (recogidas en el art. 9 LOE).
} 
tículo 70- y los específicos impuestos por la legislación sectorial en función de la petición de que se trate. En nuestro caso, es importante destacar la documentación que debe adjuntarse con la solicitud. El análisis de esta cuestión nos lleva, sin embargo, al siguiente epígrafe de este trabajo.

\section{C) Suficiencia del título para construir; el derecho de propiedad $y$ otros derechos a construir en finca ajena}

Se refiere a este requisito el artículo 9.2 a) LOE cuando literalmente establece como una obligación del promotor $<\langle$ Ostentar sobre el solar la titularidad de un derecho que le faculta para construir en él>>. Es decir, el promotor debe ser titular de un derecho sobre un solar suficiente para poder construir en él. Pues bien, parece evidente que si el texto legal articula una determinada obligación como la expuesta, a alguien debe corresponder velar por el cumplimiento de la misma y a través del cauce correspondiente. De acuerdo con la lógica del proceso de edificación, ese alguien debe ser la Administración local a través del procedimiento de solicitud de la licencia correspondiente. Recuérdese, en este sentido, que es justamente al promotor a quien también incumbe la obligación de $<$ Gestionar y obtener las preceptivas licencias y autorizaciones administrativas... > [art. $9.2 \mathrm{c}$ ) LOE]. El problema consiste pues, en primer lugar, en determinar qué derechos se pueden derivar de la facultad de edificar y, en segundo, fijar qué requisitos formales deben tener dichos derechos para poder ser apreciados favorablemente por la Administración local. Al respecto es necesario realizar dos observaciones con carácter previo, a saber:

i) Por un lado, es preciso destacar que el alcance de la intervención municipal, en modo alguno, debe ser comprensiva de un poder de calificación o «cuasicalificación» dirigido a verificar la válida definición y constitución del título esgrimido como fundamento de la voluntad de edificar que ha sido puesta de manifiesto con la solicitud de la licencia. No se trata de articular una función calificadora propia, responsabilidad, esta vez, de la Administración local. Tal labor pública está atribuida a otros funcionarios y, por tanto, no se trata de confundir las diferentes esferas competenciales. Como es sabido, la función calificadora corresponde con carácter exclusivo y excluyente al Registrador de la Propiedad.

ii) Por otro, hay señalar que la intervención local en este punto tampoco debe estar orientada a asegurar la licitud y legitimidad de la situación posesoria que fundamenta la petición. En efecto, como es sabido, el objeto de examen de la licencia ha quedado circunscrito tradicionalmente al 
cumplimiento de la ordenación urbanística, al margen de otras cuestiones de naturaleza jurídico-civil o, incluso, de carácter administrativo. De ahí justamente la cláusula de «sin perjuicio de tercero» que la praxis urbanística une al otorgamiento de las licencias de obras; éstas nunca alteran las situaciones jurídico privadas. En este sentido, se ha pronunciado la jurisprudencia contencioso-administrativa (sin ánimo de exhaustividad, véase la Sentencia emitida por el Tribunal Supremo con fecha de 19 de septiembre de 1986) que, a partir del reconocimiento de la competencia de la jurisdicción ordinaria en los temas de propiedad y posesión, ha afirmado unánimemente que la licencia municipal de obra no es título legitimador - por no suficiente-para dar derecho sobre un terreno, ya que lo único que otorga — dejando a salvo el derecho de propiedad y sin perjuicio de tercero- es un permiso o licencia para realizar una obra pero nada más, $<<.$. pues es sabido que el procedimiento de concesión municipal de obra no es el adecuado para resolver subrepticiamente los problemas de dominio o posesión pendientes $>>$.

Pues bien, el alcance de la intervención municipal debe ser comprensivo, en nuestro caso, no tanto - y por las razones expuestas- de aquellas circunstancias, cuanto, más bien, de la titularidad y existencia misma del título correspondiente, verificando que la facultad de edificación deriva del mismo.

Aclarado de esta forma el alcance de la potestad municipal en relación con la labor de verificación del título que fundamenta la solicitud de la licencia, procede determinar, siquiera sea brevemente, cuáles son tales derechos.

\section{a) Derecho de propiedad}

Resulta evidente que derecho suficiente para construir es, en primer lugar, el derecho de propiedad. De acuerdo con lo dispuesto en el artículo 348CC, se trata de <<el derecho de gozar y disponer de una cosa, sin más limitaciones que las establecidas en las leyes.>> y, como es sabido, sin perjuicio de la delimitación que del contenido de este derecho haga la legislación urbanística vigente o, en virtud de la misma, el planeamiento urbano, el ius edificandi puede formar parte del mismo. Es preciso tener en cuenta, sin embargo, que la función social de la propiedad delimita el contenido de las facultades urbanísticas y condiciona su ejercicio (art. 1, en relación con el art. 2.1 LS 98). En efecto, como destaca en este punto el Profesor PAREJo, si el objeto de la LS 98 es la definición del «contenido básico» del derecho de propiedad «de acuerdo con su función social» 
(mediante la regulación de las condiciones básicas aseguradoras de la igualdad esencial de su ejercicio en todo el territorio nacional, como debe entenderse desde luego interpretativamente conforme a la STC 164/2001), es claro que la circunscripción del ejercicio legítimo de las facultades de dicho derecho al espacio interior acotado por los «límites» determinados por la ordenación urbanística significa la delimitación por ésta de aquel contenido en atención precisamente a la expresada función social, categoría que se concreta en dos consecuencias trascendentes:

i) En primer lugar, que el contenido de dicha función delimita positivamente el ámbito de facultades «urbanísticas» del derecho de propiedad (es decir, el contenido positivo de éste en tanto que derecho subjetivo) y, por tanto, configura y en modo alguno limita, lesiona, incide o afecta negativamente algo preexistente. Pero además, y esto es decisivo, esa operación de delimitación no determina sin más la atribución automática de las facultades configuradas al titular del derecho de propiedad objeto de aquella operación. Antes al contrario, la atribución de las facultades tiene lugar por la ordenación urbanística (concretamente de la integración por la misma del régimen urbanístico del suelo) y del proceso urbanístico por ella regulado, como resulta del contenido dispositivo de la legislación urbanística.

ii) En segundo lugar, la función social condiciona el ejercicio de las facultades así delimitadas, imponiendo deberes al titular del derecho de propiedad, también en sede de definición del contenido de este último. De esta manera, el cumplimiento de estos deberes aparece, así, como condición misma para la consolidación y, consecuentemente, el ejercicio de facultades ${ }^{8}$.

\footnotetext{
${ }^{8}$ De ahí justamente que el Tribunal Constitucional haya destacado la inexistencia de un concepto unívoco del derecho de propiedad. Por el contrario, existen tantos conceptos como funcionalidades socio-económicas cumplen los bienes en el tráfico jurídico. Y en este sentido afirma (STC 37/1987, de 26 de marzo) que <<Como corolario de estas reflexiones iniciales, que juzgamos imprescindibles para situar la impugnación planteada en su verdadera perspectiva constitucional, no es ocioso añadir ahora que la propiedad privada, en su doble dimensión como institución y como derecho individual, ha experimentado en nuestro siglo una transformación tan profunda que impide concebirla hoy como una figura jurídica reconducible exclusivamente al tipo abstracto descrito en el art. 348 del CC, que los recurrentes citan en apoyo de su alegato de inconstitucionalidad. Por el contrario, la progresiva incorporación de finalidades sociales relacionadas con el uso o aprovechamiento de los distintos tipos de bienes sobre los que el derecho de propiedad puede recaer ha producido una diversificación de la institución dominical en una pluralidad de figuras o situaciones jurídicas reguladas con un significado y alcance diversos, de ahí que se venga reconociendo con general aceptación doctrinal y jurisprudencial la flexibilidad o plasticidad actual del dominio que se manifiesta en la existencia de diferentes tipos de propiedades dotadas de estatutos jurídicos diversos, de acuerdo con la naturaleza de los bienes sobre los que cada derecho de propiedad recae.
} 
En cualquier caso, es preciso destaca que el derecho de propiedad no agota las posibles relaciones jurídicas que permiten fundamentar aquel derecho y que deben ser objeto de la intervención municipal.

\section{b) Derecho de superficie y otros derechos constituidos sobre finca ajena}

Desde un punto de vista dogmático, el derecho de superficie se puede calificar como un derecho real restringido, limitativo de la propiedad del suelo, cuyo contenido consiste en la facultad de tener y mantener - por tiempo limitado o no- una edificación en suelo ajeno. Dicho derecho se fundamenta, por tanto, en la neta disociación del dominio del suelo y del aprovechamiento de este. Se trata, en definitiva de constituir un ius edificandi en suelo ajeno que, mediante la derogación temporal del principio de accesión, atribuye lo edificado al superficiario. De este modo, el derecho de superficie actúa de soporte jurídico de la plena propiedad de la edificación por parte de este último.

El Código Civil carece de una regulación concreta del derecho de superficie, si bien su mención en el artículo 1611.3 de dicha norma, la aplicación del principio de autonomía de la voluntad privada y la admisión del sistema de numerus apertus en materia de creación de derechos reales, permite en principio la constitución de derechos de superficie cuando así convenía a los sujetos interesados. Por su parte, la LS de 1956, tomando como ejemplo algunas experiencias extranjeras, intentó implantarlo en nuestro sistema jurídico-urbanístico, poniéndolo a disposición de la gestión urbanística ${ }^{9}$. No obstante, se trata de una institución que ha tenido el arraigo necesario en el

En lo que concierne a la restricción o modulización de las facultades dominicales e imposición de deberes positivos al titular, la transformación antes dicha ha afectado de una manera más intensa a la propiedad inmobiliaria, tanto a la que recae sobre suelos susceptibles de aprovechamiento urbanístico como a la propiedad de tierras agrícolas o forestales, lo que es fácilmente explicable, entre otras razones, por el carácter no renovable o naturalmente limitado en su extensión de este tipo de bienes y por la trascendencia económica que ofrece como soporte físico de las actividades productivas $>$.

${ }^{9}$ Así, la Exposición de Motivos del Texto de 1956 establecía que < < el fomento de la edificación no precisa, ni a veces aconseja, la enajenación de los terrenos; basta la constitución del derecho de superficie. La experiencia extranjera muestra las intensas posibilidades de esta figura jurídica que, a la vez que facilita la construcción, evita la especulación de edificios y terrenos de reserva, el aumento de valor del propietario. De aquí que se admita la constitución del derecho por Entidades públicas y particulares >>. Por su parte, la Exposición de Motivos de la Ley 19/1975, de 2 de mayo, tras destacar la <<creciente atención» que como instrumento de política de suelo estaba teniendo en todos los paises, afirmaba que «el derecho de superficie puede y debe ser un instrumento mediante el que, cada vez más, se procure que el derecho de propiedad urbano, una vez que entre en la esfera patrimonial de la Administración, no salga de la titularidad pública; el incremento no solo en el espacio, sino en el 
ámbito jurídico de nuestro país, circunstancia debida, seguramente, a los importantes problemas de calificación que plantea esta figura ${ }^{10}$.

En efecto, para empezar resulta que lo que hemos denominado con carácter general como derecho de superficie no es una categoría jurídica unitaria. Como reconoce unánimemente la jurisprudencia civil ${ }^{11}$, en función de la diversa naturaleza de los sujetos que en cada caso intervienen, de la actuación desarrollada por los mismos y de la finalidad perseguida, es necesario diferenciar dos clases o modalidades del referido derecho. Por un lado, el derecho de superficie urbano común o clásico que < <...por dar satisfacción a intereses puramente particulares y recaer, sobre suelos de esta naturaleza, no tiene por que verse afectada por una regulación distinta de la que establece el Derecho Civil,...>>. Por otro, el de carácter urbanístico que constituye $<<. .$. uno de los instrumentos de que la Administración desea valerse para intervenir en el mercado del suelo y promover la construcción de viviendas o de otras edificaciones determinadas en los Planes de Ordenación>>.

Ocurre, sin embargo que, desde su concepción clásica, una vez caracterizado por el elemento material del título, es decir, por la facultad de construir en finca ajena, el derecho de superficie no se diferencia de otros derechos que pueden llevar incorporada la misma facultad como puede ser el censo enfitéutico o el arrendamiento con cláusula superficiaria, según se pacte por tiempo indefinido o se convenga por tiempo determinado, títulos que, por tanto, también pueden ser esgrimidos por el solicitante de la licencia como fundamento de su petición. Tal circunstancia ha conducido a la doctrina privatista afirmar que no existe un derecho como derecho típico en cosa ajena, distinto de los restantes derechos que pueden llevar incorporada la facultad de edificar, perspectiva desde la que se sostiene la conveniencia de hablar, más bien, de títulos o derechos en cosa ajena que llevan incorporada una cláusula superficiaria que no se reducen al censo enfitéutico o al arrendamiento. Y así, la Resolución de la DGRN de 15 de mayo de $1984^{12}$ admite la inscripción de una servidumbre de construir bajo el suelo ajeno. Incluso,

tiempo, de los patrimonios públicos del suelo, debe seguir siendo pieza clave de la política urbanística».

${ }^{10}$ En relación con esta cuestión, ver J.L. DE Los Mozos; «La tecnificación del derecho de superficie», publicado en Estudios sobre el Derecho de los bienes; Edit. Montecorvo; Madrid, 1991; p. 485 y ss. y L. Díez-Picazo y A. Gullón; Sistema de Derecho Civil, Vol. III; Edit. Tecnos; Madrid, 1986; pp. 469 y ss.

${ }^{11}$ Así, las Ss. TS de 1 de febrero de 1979 —ar. 19791420 — 15 de junio de 1984 —ar. 198413243 — y 26 de noviembre de 2002 -ar. 200219935—.

${ }^{12}$ Ar. $1984 \backslash 2588$. 
tratándose del derecho de superficie constituido por Administraciones públicas sobre terrenos de su propiedad el derecho analizado se configura con rasgos próximos a una concesión sobre el dominio publico ${ }^{13}$.

\section{c) Derecho de vuelo}

A1 derecho de vuelo se refiere el artículo 16.2 del Decreto de 14 de febrero de 1947, por el que se aprueba el Reglamento Hipotecario —en adelante, RH- Tradicionalmente se ha diferenciado entre derecho de superficie y derecho de vuelo con fundamento en la circunstancia de que su constitución se realice sobre un suelo ajeno sin construir (se hablaba entonces de derecho de superficie) o sobre un inmueble ya construido, como facultad de levantar nuevas plantas (derecho de vuelo). A partir de la doctrina emitida por la DGRN ${ }^{14}$ 1a doctrina «ius privatista» centra su atención a la hora de calificar un determinado derecho como derecho de superficie o derecho de vuelo, sin embargo, en la atribución o no de una cuota sobre el suelo al concesionario del derecho ${ }^{15}$. De esta forma, si en la concesión del derecho se atribuye al concesionario un derecho sobre suelo ajeno que, consecuentemente, pasa ser elemento común de la futura propiedad horizontal constituida sobre la edificación, se trata de un derecho de vuelo. En caso contrario, se trata de un derecho de superficie. Es posible, por tanto, constituir un derecho de superficie cuyo objeto sea levantar nuevas plantas en un edificio ya existente. En cualquier caso, depende de la voluntad de las partes intervinientes la constitución en favor de tercero ya de un derecho de vuelo sobre algunas dependencias o plantas del edificio a construir por dicho sujeto, ya de un derecho de superficie con cláusula de reversión limitada a las dependencias o plantas que desee reservarse el concedente del derecho ${ }^{16}$.

\footnotetext{
${ }^{13}$ En este sentido, A. Carrasco Perea, Derecho de la construcción y la vivienda, edit Dilex, S.L.; Madrid, 1998; p. 155 y ss.

${ }^{14}$ Resolución de 5 de febrero de 1986 (Ar 1986\1006).

${ }^{15}$ En este sentido, véase A. CARrasco Pérez, Derecho de la construcción...; pp. 165 y ss.

${ }^{16}$ La praxis registral ha determinado diferentes formas típicas de constitución del derecho analizado. Siguiendo al autor citado en la nota anterior podemos citar las siguientes a saber:
}

a) Reserva del promotor de propiedad horizontal. El propietario del solar que declara la obra nueva y otorga el título constitutivo de la propiedad horizontal se reserva a su favor el derecho de construir nuevas plantas, sin constituir para ello el consentimiento unánime de la junta de propietarios que se constituya en el momento.

b) Reserva del cedente del solar. El propietario de un solar que cede la propiedad del mismo a un promotor inmobiliario se puede reservar el derecho de vuelo sobre determinadas plantas o dependencias del edificio a construir. 


\section{d) Permuta de solar por piso futuro}

De acuerdo con lo dispuesto en el artículo $1538 \mathrm{Cc},<<$ La permuta es un contrato por el cual cada uno de los contratantes se obliga a dar una cosa para recibir otra >>, en nuestro caso, el cedente transmite la propiedad del solar y el cesionario se compromete a transmitirle determinadas unidades inmobiliarias en el futura ${ }^{17}$. En realidad se trata de un trueque de

c) Reserva del donante del edificio. El donante de un inmueble construido puede reservarse el derecho de elevar nuevas plantas en el futuro sobre el edificio donado, adquiriendo la propiedad de las mismas.

d) Enajenación del derecho de vuelo a cambio de pisos futuros. El titular del solar retiene en este caso la propiedad del mismo, y constituye en favor del constructor un derecho real para construir sobre el mismo. Éste hace suyas determinadas plantas y el constituyente del derecho adquiere la propiedad residual.

e) Constitución de derecho de vuelo en favor de un tercero por la comunidad de propietarios, siempre que el acuerdo se tome por unanimidad.

f) Donación del derecho de vuelo. Se trata de la constitución a título gratuito de un derecho real sobre cosa ajena.

g) Constitución recíproca del derecho de vuelo entre comuneros. Si varios sujetos que forman una comunidad sobre un solar y quieren construir un edificio con atribución anticipada a cada uno de ellos de pisos o locales concretos.

Es preciso destacar en este lugar que los derechos reales en modo alguno constituyen un número cerrado. Así se expresa el art. 2.2 LH cuando afirma que en el Registro de la Propiedad se inscribirán los títulos en que se constituyan, reconozcan, transmitan, modifiquen o extingan $<<$ derechos de usufructo, uso, habitación, enfiteusis, hipoteca, censos y cualesquiera reales >>. Y en el mismo sentido se ha pronunciado la DGRN cuando se crea un derecho real distinto a los legales y se pretende su inscripción registral, si bien con importantes cautelas, se muestra siempre favorable a su inscripción.

${ }^{17}$ Como en el caso anterior, la práctica ha ido articulando diferentes modulaciones de este derecho. Entre éstas podemos citar las siguientes:

a) Permuta de solar por participación en porcentaje de lo construido, ya sea una cuota indivisa en el edificio, ya sea un predeterminado de unidades inmobiliarias. En cualquier caso, a diferencia del supuesto anterior, da lugar a la constitución de una comunidad sobre la obra y, por tanto, frente a terceros acreedores existe una sociedad intenta entre el cedente y cesionario. Si el porcentaje participado es de la obra.

b) Cesión de derecho de vuelo a cambio de viviendas o locales futuros. El permutante retiene la propiedad del solar hasta que se otorgue la declaración de obra nueva y división horizontal, en la que tendrá que concurrir con el titular del derecho de vuelo, ya que la propiedad inicial del solar se debe transformar en una cuota de copropiedad sobre el nuevo elenco común.

c) Reserva de vuelo y transmisión de propiedad del solar con prestación subordinada de obra. El cedente se reserva el derecho de vuelo sobre determinados pisos o locales y el promotor que deviene en propietario del solar contrae con aquel las obligaciones propias del contratista de obras.

d) Autopromoción en comunidad. Es posible por último que los comuneros pacten en la escritura de obra nueva la atribución privativa a cada uno de ellos de pisos o locales que deben corresponderles, sin necesidad de llegar a dicho resultado final por medio de una disolución de comunidad 
derechos de propiedad que puede tener por objeto tanto cosas como derechos. La permuta tiene pues cierta semejanza con la compraventa de la que se diferencia esencialmente en la falta de precio.

Pues bien, el problema que pueden plantear dichos derechos en relación con este orden de ideas es su forma de constitución en tanto que, como consecuencia del giro jurídico-económico del que van a ser objeto, tienen que producir efectos jurídicos generales. En otras palabras y concretando la cuestión; si la Administración local para poder estimar como suficiente el derecho esgrimido debe acudir a especiales requisitos formales (escritura pública e inscripción en el Registro de la Propiedad) o basta con atender a las reglas generales.

$\mathrm{Al}$ respecto es preciso recordar que la exigencia de forma escrita en los actos y contratos que tienen por objeto la creación, transmisión, modificación o extinción de derechos reales a que se refiere el artículo $1280.1 \mathrm{Cc}$, salvo en el caso de los contratos estrictamente formales, es decir, aquellos en que la Ley exija dichos requisitos como elemento esencial, imponiéndolos como ad substantiam, bajo pena de nulidad, no tiene el alcance de forma solemne que pudiera afectar a la eficacia obligatoria del contrato, constituyendo, más bien, una mera facultad a favor de los contratantes y no una obligación que al no hacer uso de ella no enerva la acción que corresponda para hacer efectivo el derecho nacido de la convención, como también que la falta de escritura no obsta a la eficacia del contrato si concurren las condiciones esenciales para su validez. Ocurre algo parecido en el caso de la inscripción registral. En principio, dicha inscripción tiene un alcance meramente declarativo y no constitutivo y, desde esta perspectiva, el artículo 2 del Decreto de 8 de febrero de 1946 por el que se aprueba el Texto Refundido de la Ley Hipotecaria - en adelante, LH- declara susceptibles de inscripción, por un lado, los títulos traslativos o declarativos de dominio de inmuebles o derechos reales impuestos sobre los mismos; por otro, los títulos en que se constituyan, reconozcan, transmitan, modifiquen o extingan derechos de usufructo, uso, habitación, enfiteusis, hipoteca, censos, servidumbres y cualesquiera otros reales. Igualmente, el RH (art. 7) admite la inscripción de cualesquiera otros títulos relativos a derechos de la misma naturaleza (real) que, sin tener nombre propio en Derecho, modifiquen, desde luego, o en el futuro, algunas de las facultades del dominio sobre inmuebles o inherentes a derechos reales.

sobre el edificio futuro. También pueden pactar lícitamente una constitución recíproca de derechos de vuelo en favor de cada uno de los partícipes que recaerán sobre los pisos o locales inicialmente asignados. 
Pues bien, solamente el derecho de superficie de carácter urbanístico y el derecho de vuelo precisan en todo caso (por imperativo de los arts. 288.1 TRLS 92, precepto que tiene carácter pleno con las consecuencias que se derivan de tal calificación y $16.1 \mathrm{RH}^{18}$ ) su formalización en escritura pública y como requisito de eficacia su inscripción en el registro. En los demás casos, un derecho de superficie constituido entre particulares no requiere para su existencia ni inscripción en el Registro de la Propiedad, ni para su constitución escritura pública como requisito ad solemnitatem. Y ello porque, a juicio del TS, < <..precisamente en atención al principio espiritualista de libertad de contratación que proclama el artículo 1278 del Código Civil, según el cual - como recuerda la sentencia de 15 de junio de 1984- la eficacia de los contratos no depende de sus formas externas, sino de la concurrencia de las condiciones necesarias que para la validez de los mismos establece el artículo 1261 del mismo Cuerpo legal salvo que se trate de contratos estrictamente formales, en los que el requisito de forma es exigible ad substantiam y no solamente ad probationem ${ }^{19}$. En otras palabras, la constitución del derecho de superficie no requiere con carácter necesario el otorgamiento de escritura pública, o sea, a modo ad solemnitatem, salvo en los supuestos concretos en los que así se establece. En consecuencia, cuando tal exigencia no venga legalmente

\footnotetext{
${ }^{18}$ Recuérdese que, a tenor de dicho precepto reglamentario, $<<$ Para su eficaz constitución deberá inscribirse a favor del superficiario el derecho de construir edificios en suelo ajeno y el de levantar nuevas construcciones sobre el vuelo o efectuarlas bajo el suelo de fundos ajenos. Los títulos públicos en que se establezca dicho derecho de superficie deberán reunir, además de las circunstancias generales necesarias para la inscripción, las siguientes:
}

A) Plazo de duración del derecho de superficie, que no excederá de 50 años. Transcurrido el plazo, lo edificado pasará a ser propiedad del dueño del suelo, salvo pacto en contrario.

B) Determinación del canon o precio que haya de satisfacer el superficiario, si el derecho se constituye a título oneroso, pudiéndose estipular la reversión del todo o parte de lo edificado a favor del dueño del suelo al expirar el plazo convenido.

C) Plazo señalado para realizar la edificación, que no podrá exceder de cinco años; sus características generales, destino y costo del presupuesto.

D) Pactos relativos a la realización de actos de disposición por el superficiario.

E) Garantías de trascendencia real con que se asegure el cumplimiento de los pactos del contrato. No serán inscribibles las estipulaciones que sujeten el derecho de superficie a comiso >>.

${ }^{19}$ De acuerdo con la posición expresada por el TS $<<\ldots$ los preceptos imperativos de la normativa mencionada, al constituir una importante excepción de principio espiritualista de libertad de contratación y de autonomía de la voluntad privada, solamente pueden encontrar justificación en aquellas ocasiones o para aquellos supuestos en que se hallen en juego finalidades de interés público, como sucede cuando la Administración decide utilizar el derecho de superficie como instrumento de intervención en el mercado del suelo, careciendo en cambio del menor fundamento para ser impuestos en las relaciones contractuales de particulares que no tienden a conseguir finalidades sociales, sino auténticamente privadas. >>. 
establecida rigen las reglas generales que establecen al respecto los artículos 1278,1279 y 1280 del Cc y, por tanto, el principio espiritualista de la libertad de contratación a que hace referencia el artículo 1278 del mismo cuerpo legal que consagra que la eficacia de los contratos, expresión de la voluntad común de los contratantes, no depende de sus formas externas, sino de las condiciones necesarias para su validez, previstas en el artículo $1261 \mathrm{Cc}$ dado que se debe dar preferencia a la libertad de contratación ${ }^{20}$.

Igualmente, en el censo enfitéutico debido a su larga duración (art. $1628 \mathrm{Cc}$ ) y en la servidumbre con cláusula superficiaria (dado que normalmente la forma de constitución parece que será mediante contrato art. $1280.1 \mathrm{Cc}$ - es precisa la escritura pública. En los demás casos como es sabido, la partes pueden, todo lo más, compelerse recíprocamente, bien a dar forma escrita al contrato, bien a dar la forma especial requerida por ley para hacer efectivas las obligaciones contraídas ${ }^{21}$.

Ocurre, sin embargo, que las exigencias derivadas del tráfico jurídico van a determinar que el requisito de la inscripción registral sea una necesidad ineludible en todos los demás casos, pues sólo de esta manera van a producir efectos frente a terceros. y esta circunstancia implica, a su vez, la previa escrituración pública de los mismos. Así lo dispone el artículo LH cuando dispone con carácter imperativo que los documentos inscribibles han de constar en escritura pública, ejecutoria o documento auténtico expedido por Autoridad judicial o por el Gobierno o sus Agentes en la forma prescrita. En efecto, la necesidad de dotar al Registro de la Propiedad de la máxima exactitud posible con el fin de garantizar la seguridad

\footnotetext{
${ }^{20} \mathrm{El}$ derecho de superficie se debe inscribir como todo derecho en cosa ajena, como tal derecho o como otro tipo pero con cláusula superficiaria en el folio de la finca gravada al igual que la declaración de obra nueva. Solamente, si se constituyese posteriormente un régimen de propiedad horizontal, se abre folio registral propio para la edificación. Tratándose del derecho de vuelo, como derecho sobre cosa ajena, se inscribe en el folio de la finca sobre la que tendrá lugar la futura construcción. Cuando ésta se realice surgirá una nueva entidad registral que requerirá de un folio independiente. Así, si el suelo no estaba edificado, el titular del derecho de vuelo y, en su caso, el constituyente en su calidad de titular de los elementos o unidades residuales, estarán legitimados para declarar la obra nueva, inscribir el edificio en régimen de propiedad horizontal y, en su caso, proceder a inscribir cada unidad registral. En caso de que el edificio estuviese constituido ya en tal régimen de propiedad horizontal, se debe proceder a una modificación del título constitutivo y a la creación, de acuerdo con lo dispuesto en el art. 8.5. ${ }^{\circ} \mathrm{LH}$ de tantas fincas registrales nuevas como pisos o locales resulten del ejercicio del derecho. A diferencia del derecho de superficie, resulta esencial que las nuevas unidades registrales se inscriban como tales a partir de la inscripción como finca del edificio, que se deberá practicar en el mismo folio en que figura inscrito el solar sobre el que se concedió el derecho.

${ }^{21}$ Así se expresan entre otras las Ss. TS de 5 de diciembre de 1940 (ar. 1940\1129), 6 de marzo de 1947 (ar. 1947\344), 5 de enero de 1957 (ar. 1957\126), 15 de junio de 1984 (ar. 1984\3243).
} 
del tráfico jurídico, determina que los asientos que se deban practicar sólo se puedan verificar a partir de los documentos que reúnan las condiciones necesarias de autenticidad, es decir, de los que el Derecho registral denomina títulos en sentido formal que son los documentos en los que quedan plasmados los actos o negocios jurídicos de los que deriva una modificación jurídico real (títulos de adquisición del dominio o de constitución, modificación o extinción de derechos reales) por contraposición a los títulos en sentido material que son propiamente dichos actos y negocios jurídicos. Son los primeros los que tienen acceso al registro, los que son objeto de calificación del Registrador y sobre los que se practica el asiento. El requisito de la forma actúa aquí como elemento ad probationem; es requerido como prueba del negocio. No condiciona la eficacia negocial del mismo pues se establece para que el negocio pueda ser probado únicamente a través de la forma prescrita legalmente. La trascendencia de la publicidad en la transferencia y en el gravamen del dominio y de los derechos reales no deja lugar a dudas. El alcance de la seguridad en el tráfico deriva de la publicidad, del desarrollo de la circulación de la riqueza y del crédito territorial, factores de carácter económico deseables en toda sociedad desarrollada, y ello resulta evidente en el caso de la transmisión de bienes inmuebles.

\section{D) El proyecto de edificación}

Como es sabido, toda licencia debe concretar y definir el contenido de la petición realizada. Esta función es la que cumple, justamente, el proyecto de edificación, instrumento que, consecuentemente, tiene una trascendencia pública aunque tenga una base jurídica privada, por imperativo legal, ya que por sí mismo no legitima a su autor o promotor a la ejecución de la edificación ${ }^{22}$. Una vez integrado el proyecto en el contenido documental de la licencia (en su versión originaria o modificada — en virtud de los trámites propios del procedimiento-) adquiere, además, la condición de documento público con todas las consecuencias que tal condición conlleva. Por ello, como destaca el TS, la licencia de obra, es un acto en blanco cuyo contenido se integra por remisión al proyecto autorizado ${ }^{23}$.

El proyecto de edificación es definido por el artículo 4 de la LOE como «... el conjunto de documentos mediante los cuáles se definen y determi-

\footnotetext{
22 Téngase en cuenta toda la normativa urbanística autonómica que así lo exige, como las regulaciones locales o el propio artículo 9.11 RSCL de 1955, vigente aún con carácter supletorio.

${ }^{23}$ Véase STS 21 de enero de 1992 (RJ 1992, 718).
} 
nan las exigencias técnicas de las obras contempladas en el artículo», documentos (exigidos por la legislación urbanística autonómica y, en su caso, por el Decreto 462/1971, que aprueba las normas de redacción de proyectos y dirección de obras de edificación) y que deben cumplir tanto la normativa técnica estrictamente edificatoria (recogida en el art. 3 de la LOE) como la urbanística aplicable al suelo concreto de que se trate. Se trata, de esta forma, que el proyecto sea completo y suficiente para, por un lado, ofrecer a la Administración los datos precisos para decidir sobre la viabilidad urbanística (por ello en algunos casos el TS consideró que el Proyecto Básico no era suficiente para otorgar la licencia ${ }^{24}$ ) y, por otro, servir para que un facultativo distinto del proyectista pueda ejecutarlo (Director de obra, art. 11).

De esta forma, se puede afirmar que la función primaria del proyecto es definir, documentándolas, las operaciones precisas para la ejecución de la obra y asegurar, así, el cumplimiento del fin del proceso de edificación: la construcción del edificio diseñado, sirviendo de criterio y guía para la actuación tanto del director de obra (que ha de dirigir de conformidad con el proyecto: art. 12.1 LOE); como del director de la ejecución de la obra [que ha de asegurar la correcta ejecución y disposición de los materiales de los elementos constructivos y de las instalaciones de acuerdo con el proyecto y las instrucciones del director de obra: art. 13.2 c) LOE] y del constructor [que ha de ejecutar la obra con sujeción al proyecto y a las instrucciones del director de la obra con sujeción al proyecto y a las instrucciones del director de obra y del director de la ejecución de la obra: art. 11.2 a) LOE]. De ahí que el proyecto pase a formar parte, una vez finalizada la obra, de la documentación de la obra ejecutada, que integra el libro del edificio (de acuerdo con el art. 7 LOE y, la normativa autonómica). En cualquier caso, se deben indicar, las siguientes circunstancias, a saber:

i) El proyecto regulado por el artículo 4 de la LOE es aquel que tiene por objeto, sólo y exclusivamente, las obras reguladas por la propia LOE como de edificación (art. 2.2. LOE).

ii) El proyecto puede ser único o parcial. En el primer caso, engloba toda la obra de edificación (entendiendo por obra de edificación, la acción y el resultado de producir un edificio). Es parcial si se puede desagregar su proyectación en proyectos de obras de edificación y proyectos parciales de complemento o desarrollo (art. 4 en relación con los arts. 5 y 6 LOE),

\footnotetext{
${ }^{24}$ STS 5 de diciembre de 1983 (RJ 6948) y de 12 de julio de 1994 (5537). Si bien en otras sí lo considera suficiente (STS 25 de enero de 1988 (ar. 1988/423).
} 
iii) Finalmente, hay que señalar que el proyecto es un «conjunto de documentos» y no sólo uno, que debe definir y determinar las exigencias técnicas y justificar todas las soluciones propuestas. Se integra, por tanto, por toda la documentación exigida (arts. 54 y 10 LOE) y otros documentos establecidos por la legislación autonómica ${ }^{25}$. Pues bien, es preciso destacar que aquella función general se despliega mediante el cumplimiento de una serie de requisitos concretos cuya comprobación corresponde realizar a la Administración local. Veamos algunos de ellos.

\section{a) Control urbanístico}

El control de la viabilidad urbanística se realiza, en sede municipal, sobre el proyecto técnico, que se debe referir a un concreto e individualizado terreno y ser comprensivo de los requisitos urbanísticos precisos, de tal forma que permitan a la Administración fiscalizar si la obra que se pretende ejecutar se adapta en cuanto a emplazamiento, alineaciones, volúmenes, altura, etc., a las previsiones del planeamiento vigente ${ }^{26}$. La propia LOE exige, en este sentido, en concordancia con la normativa autonómica ${ }^{27}$, que tanto el proyectista como el Director de la ejecución de la obra redacten y ejecuten el proyecto con sujeción a la normativa urbanística (arts. 10.1 y 12.1). Incluso, en algunas regulaciones autonómicas esta exigencia es aún más estricta pues exigen que se adjunte conjuntamente con el proyecto de la edificación otros proyectos relevantes para la ordenación urbanística ${ }^{28}$.

\section{b) Control de cumplimiento de normativa técnica}

De acuerdo con lo dispuesto en la LOE el proyecto debe justificar «... técnicamente todas las soluciones propuestas de acuerdo con las especificaciones requeridas por la normativa técnica aplicable» (art. 4). Esta obligación, que lógicamente recae sobre el proyectista (quien debe redactar el proyecto «...con sujeción a la normativa técnica» (art. 10.1 de dicho texto legal), también debe ser observada y, consecuentemente, ejecutada por el Director de la Obra («...dirige el desarrollo de la obra

\footnotetext{
${ }^{25}$ Como ejemplo baste citar el art. 5.4 de Ley 2/1999, de 17 de marzo, de Medidas para la Calidad de la Edificación de Madrid —en adelante, LMCEm — que exige el presupuesto.

26 Véase sentencia del TS de3 de mayo de 1982.

${ }^{27}$ Ley 3/1987, de Asturias (art. 2), Ley 2/2001, de 25 de junio de Cantabria (art. 190).

28 (Art. 154.1 .b) LmS01.
} 
en los aspectos técnicos... » art. 12.1) y por el Director de la ejecución de la obra («...función técnica de dirigir la ejecución material de la obra...» art. 13.1). al Ayuntamiento corresponde, por tanto, velar porque los proyectos cumplan esta exigencia; exigencia, por lo demás, que persigue garantizar que la edificación sea segura y adecuada al fin propuesto.

Pues bien, estos requisitos comprenden, conforme con el artículo 3 LOE, tanto los aspectos de funcionalidad (relativos a los espacios y dotación de instalaciones, los de accesibilidad para las personas con movilidad reducida o los de posibilidad de acceso a los servicios de telecomunicación) ${ }^{29}$ como los de seguridad (estructural, incendio y de utilización) y los de habitabilidad (higiene, salud y protección del medio ambiente, protección contra el ruido, ahorro energético y aislamiento térmico y otros aspectos funcionales). Los dos últimos, es decir, los relativos a las condiciones de seguridad y de habitabilidad, se recogerán en el futuro Código Técnico de la edificación definido como aquel que «...establezca las exigencias que deben cumplir los edificios en relación con los requisitos básicos...» (art. 3.2 y DF2 ${ }^{\mathrm{a} 30}$ ), pudiendo «... completarse con las exigencias de otras normativas dictadas por las Administraciones competentes...». Conviene recordar que las distintas Comunidades Autónomas, haciendo uso de las competencias asumidas con carácter exclusivo en materia de vivienda $y$, en virtud de los traspasos efectuados por el Estado en materia de calidad de la edificación, han adoptado un conjunto de normas de carácter sustantivo reguladoras de algunos de aquellos aspectos técnicos de la edificación, llegando a exigir, incluso, la inclusión de un programa de control de calidad o un informe emitido por el órgano autonómico competente relativo a dichos extremos. Tampoco debemos olvidar la competencia de la Administración Local en este ámbito que, con pleno respeto a las disposiciones estatales y autonómicas, puede dictar en materia de seguridad, salubridad, habitabilidad y calidad de las construcciones y que deben ser recogidas en las Ordenanzas de ámbito local ${ }^{31}$.

\footnotetext{
${ }^{29}$ Esta cuestión se debe regir por su normativa específica, principalmente, por la necesidad de respetar el marco de competencias existente a la hora de regular las diferentes cuestiones relativas a dichos conceptos que, aun relacionadas con la calidad de lo construido, se apartan de las exigencias que normalmente ha tratado la normativa básica de la edificación referida más bien a cuestiones de seguridad, salubridad, ahorro de energía, etc.

${ }^{30}$ Hasta tanto se apruebe el mismo se aplican las normas básicas de la edificación y normativa técnica de obligado cumplimiento (art. 3.2 y DF primera de la LOE).
}

${ }^{31}$ Véase en este sentido la definición de Ordenanza de la edificación. 


\section{c) Confección por profesional competente}

El proyecto técnico no sólo debe cumplir, como ya nos consta, con todas las exigencias técnicas vigentes. Para ser válido precisa, también, ser elaborado por un técnico competente. Este sujeto se denomina proyectista y es definido por la propia LOE como aquel que «por encargo del promotor y con sujeción a la normativa técnica y urbanística correspondiente, redacta el proyecto». No obstante, son considerados proyectistas también aquellos técnicos que redactan los proyectos parciales o partes que complementen el proyecto de forma coordinada con el autor del proyecto principal (art. 10.1). A tal efecto, sólo son considerados técnicos competentes los arquitectos e ingenieros de primero y segundo ciclo, siempre dentro de las determinaciones legales vigentes para cada profesión y de las respectivas especialidades y competencias específicas (arts. 2, 4 y 10 de la LOE) y los técnicos que conforme a la legislación específica se encuentran habilitados para la redacción de proyectos parciales o complementaria del proyecto.

Se debe señalar, en este punto, que la LOE concreta, no obstante, las competencias de cada técnico en función del uso al que vaya a ser destinada la edificación, si bien hay que advertir de que el sistema competencial articulado por el texto legal no supone tanto una innovación respecto del sistema vigente con anterioridad sino, más bien, cierta clarificación del deslinde competencial. En este sentido, se debe destacar de acuerdo con el texto legal que los Arquitectos cuentan con un reconocimiento de competencia universal en materia de elaboración de proyectos y dirección de la edificación en términos de exclusividad cuando se trata de un inmueble destinado a usos administrativos, sanitario, religioso, residencial en todas sus formas, docente y cultural. Tratándose de usos aeronáuticos; agropecuarios; de la energía; de la hidráulica; minero; de las telecomunicaciones (referido a la ingeniería de las telecomunicaciones); del transporte terrestre, marítimo, fluvial y aéreo, forestal; industrial; naval; de la ingeniería de saneamiento e higiene; y accesorio a las obras de ingeniería y su explotación, el Arquitecto es también competente para proyectar, si bien, en concurrencia con otros titulados técnicos superiores (ingenieros) o, incluso, de grado medio (ingeniero técnico), en función de la respectiva especialidad y competencia específica. Solamente en el resto de edificaciones cuyos usos sean distintos a los mencionados con anterioridad, los sujetos competentes para elaborar proyectos pueden ser tanto los titulados superiores (arquitectos e ingenieros) como los de grado medio (arquitectos e ingenieros técnicos) siempre, claro está, de acuerdo con la respectiva especialidad y competencia específica (arts. 2, 10 y 11 LOE). 
En cualquier caso se debe indicar que el proyecto no debe ir firmado siempre por un solo proyectista. La legislación vigente (así, normas que regulan la profesión de los proyectistas y la propia LOE) permite que un proyecto sea elaborado por varios sujetos, en cuyo caso la titularidad del mismo corresponde a todos los profesionales que lo redactan y, consecuentemente, lo firman. En este supuesto, la responsabilidad es solidaria al expresar la LOE que «Cuando el proyecto haya sido contratado conjuntamente con más de un proyectista, los mismos responderán solidariamente» (art. 17.5). Supuesto distinto a dicha hipótesis es que el proyecto de edificación se vea complementado con otro proyecto o proyectos parciales. En este caso existen varios proyectistas que firman proyectos distintos y, por tanto, cada proyectista asume la titularidad de su propio proyecto, cualquiera que sea su alcance y su propia responsabilidad. La única obligación conjunta es la de coordinar sus respectivas actuaciones (arts. 4.2 y $10.1 \mathrm{LOE})$.

Pues bien, es preciso destacar que en este orden de cosas, el Ayuntamiento cumple una función importante, pues dentro de la función de intervención que le compete, es órgano habilitado para verificar la «habilitación legal del autor o autores del proyecto» ${ }^{32}$. En este sentido es preciso destacar que la idoneidad del proyecto $\mathrm{y}$, en consecuencia, la garantía de los intereses generales implicados (seguridad para las personas y bienes y calidad de la edificación) depende de la idoneidad del proyectista. Por ello el TS ${ }^{33}$ reconoce a la Administración pública la facultad de controlar que el proyecto haya sido redactado por técnico competente, sin que el visado colegial exima de la comprobación de este extremo, de tal forma que la no verificación de la suficiencia de título supone una dejación en el servicio al interés público que es consustancial a la Administración pública. De ahí que la licencia otorgada sobre la base de un proyecto redactado por un técnico legalmente incompetente sea igualmente ilícita.

\section{d) Contar con visado profesional}

Todo proyecto confeccionado por profesionales en el ejercicio libre de su profesión precisa para tener eficacia contar con el visado correspondiente de la organización colegial a la pertenezca el profesional autor de

\footnotetext{
32 Normativa autonómica que exige expresamente esta verificación (art. 152.a) LSm01.

${ }^{33}$ STSs de 30 de enero de 1990, de 20 de mayo de 1993, de 26 de diciembre de 1995 y de 29 de enero de 1996, entre muchas otras.
} 
dicho proyecto (art. 10.2.b) ${ }^{34}$. En este sentido, el visado colegial se puede referir a dos aspectos. Por un lado, el visado corporativo que supone una revisión del trabajo profesional (donde se controla tanto la idoneidad del técnico como la corrección e integridad formal del trabajo a las normas vigentes ${ }^{35}$ ); por otro, el urbanístico que, si bien cada día más en desuso, se refiere a la adecuación del proyecto a la normativa urbanística. La falta del primero determina que la Administración no pueda conceder la licencia o si ésta ha sido concedida su anulabilidad, pues, como ha reconocido el TS ${ }^{36}$, el visado colegial representa el ejercicio de una función pública que trasciende del marco interno de las relaciones entre el Colegio y los colegiados, al significar un control del ejercicio de la profesión que, a diferencia de lo que ocurre con el visado urbanístico, no puede ser llevado a cabo por otra Administración Pública que el Colegio profesional correspondiente, por lo que su omisión determina la anulabilidad de los actos administrativos que se hubieran adoptado, es decir, de las licencias de obras concedidas. No obstante, se debe destacar que el visado nunca exime al Ayuntamiento de la obligación de examinar el proyecto en toda su extensión (en especial, el cumplimiento de la legalidad urbanística) ${ }^{37}$.

\section{E) EI mantenimiento del edificio}

El artículo 16 LOE concreta para los propietarios y usuarios de los inmuebles el deber de conservación, mantenimiento y uso adecuado de la edificación, obligación que se entiende cumplida si se siguen las instrucciones contenidas en la documentación de obra ejecutada que constituye el Libro del Edificio (art. 7). Esta obligación viene a complementar el tradicional deber de conservación previsto por la legislación urbanística que impone a los propietarios de las edificaciones el deber de mantener éstas en las necesarias condiciones de seguridad, de salubridad y de ornato

\footnotetext{
${ }^{34}$ En este supuesto es importante destacar que no requieren visado colegial los proyectos elaborados por personal de la Administración, en los que el control es desarrollado por las Oficinas o unidades de supervisión de proyectos (art. 128 del Real Decreto Legislativo 2/2000, de 16 de junio, por el que se aprueba el texto refundido de la Ley de Contratos de las Administraciones Públicas.

35 Véase, en este sentido, Ley de Colegios profesionales de 13 de febrero de 1974 (y sus modificaciones) y STS de 25 de septiembre de 1997 (RJ 1997/6603) o de 21 de marzo de 2002 (RJ 2002/3996).

${ }^{36}$ STSs de 3 de julio de 1996 (RJ 1996 6129), de 2 de mayo (RJ 1997\3919), de 25 de septiembre de 1997 (RJ 1997\6603), de 14 de octubre de 1998 (RJ 1998\ 7161) y de 28 de julio de 2001 (RJ 200118324).

${ }^{37}$ Es, en este sentido, jurisprudencia reiterada [STSs de 23 de junio de 1998 y 1992 (RJ 1998/ 5439 y 1992/6170].
} 
público ${ }^{38}$. Recordemos que se trata de un deber de carácter estatutario y objetivo, es decir, su imputación recae sobre la persona que en cada momento ostenta la titularidad dominical del bien inmueble, se trata, por tanto, de una obligación propter rem y su actualización se produce por el solo hecho de la aparición en el inmueble de ciertos deterioros que precisan una reparación con el fin de mantener en todo momento las condiciones requeridas para la habitabilidad o el uso efectivo.

Pues bien, la responsabilidad municipal, que exija a los titulares dominicales de los inmuebles de que se trate, implica, en este caso, que mantengan sus propiedades en el debido estado, con arreglo a la normativa y las Ordenanzas vigentes ${ }^{39}$. No obstante, se debe destacar que el artículo 16 de la LOE amplía el ámbito de sujetos obligados, pues, no sólo impone dicho deber a los propietarios sino, también, a los usuarios (sean o no propietarios). Tal circunstancia trae causa de que el citado artículo concreta los deberes de uso y mantenimiento como límites del régimen de responsabilidad y garantías articulado por el texto legal. Por este motivo, obliga a que el promotor facilite esta documentación al adquirente (art. 9.2 e) y éste, a su vez, al usuario (art. 16). Se trata de que estos sujetos puedan conocer el uso y mantenimiento adecuado de los edificios, de tal forma que el incumplimiento de dichas previsiones pueda ser causa de exoneración de las responsabilidades establecidas en la LOE (art. 17). Como indica el propio texto legal, la prueba de que los daños fueron ocasionados por un acto de tercero o por el propio perjudicado (al no utilizar o conservar correctamente el edificio) exime de responsabilidad a los agentes de la edificación y, también, determina la pérdida de las garantías obligatorias [19.9 e) y h)]. Ello es así porque, como recordaremos, el sistema de responsabilidad previsto por la LOE es exigible de forma individual y personal, por actos $\mathrm{u}$ omisiones propios o de personas por las que, con arreglo al texto legal, se deba responder (art. 17.2). Por consiguiente, los actos del propietario o usuarios que, por lo demás, no son agentes de la edificación y de cuyos actos no se responsabiliza legalmente a los agentes de la edificación, deben ser considerados actos de tercero o del propio perjudicado ya que rompe la relación de causalidad.

Es preciso destacar la labor que le corresponde a la Administración local en este ámbito. En principio y tratándose la confección, la entrega y la recep-

\footnotetext{
${ }^{38} \mathrm{Al}$ respecto toda la normativa urbanística autonómica y el artículo 10 LPH.

${ }^{39}$ Son numerosas las Sentencias del Tribunal Supremo que así lo reconocen: STS de 8 de noviembre de 1983, de 10 de marzo de 1983, de 9 de julio de 1984, de 22 de enero, de 14 de julio de 1992 , de 17 de mayo y de 9 de diciembre de 1993 o, más recientemente, de 17 de junio de 1997.
} 
ción de la Documentación de obra ejecutada y del Libro del Edificio de una obligación legal impuesta a los agentes de la edificación la Administración no se encuentra habilitada para intervenir. No obstante, algunas Comunidades Autónomas han concretado para la Administración local una función de supervisión de la existencia y, en algún caso, de guarda de los mismos ${ }^{40}$.

Recordemos que la documentación que el promotor debe facilitar a los propietarios se denomina «Documentación de la obra ejecutada» que constituirá, necesariamente, una parte del Libro del Edificio junto con la información que la Administración correspondiente determine en sus normas de desarrollo y aquella otra que el promotor, en su caso, considere relevante incluir. De conformidad con la LOE, la citada Documentación de obra ejecutada se integra con el proyecto (con todas las modificaciones aprobadas), el acta de recepción (art. 6), la relación identificativa de los agentes que han intervenido en el proceso de edificación (arts. 8 a 15 LOE) y las instrucciones de uso y mantenimiento del edificio y sus instalaciones. En relación con el proyecto que menciona el artículo 7, se debe destacar que no comprende sólo el proyecto principal de la edificación, sino que de una interpretación conjunta de los artículos 4 y 7 de la Ley, comprende «el conjunto de documentos mediante los cuáles se definen y determinan las exigencias técnicas... » y los otros «proyectos parciales $u$ otros documentos técnicos sobre tecnologías específicas o instalaciones del edificio» (art. 4 LOE). Existe un principio de unidad de proyecto, pues la LOE exige un resultado a sus agentes, principalmente al promotor y en especial al Director de la obra que debe «coordinar» la intervención de otros técnicos (proyectistas parciales o técnicos) para «...asegurar (la) $s u$ adecuación (de la edificación) al fin propuesto» (art. 12). El segundo documento que la LOE menciona es el acta de recepción, regulada en el artículo 6 y constituye un documento de gran trascendencia no sólo porque acredita la entrega del constructor al promotor y, por tanto, el cumplimiento de las obligaciones contraídas por ambos ${ }^{41}$ sino, también, por-

\footnotetext{
40 Téngase en cuenta la Ley 24/1991, de 29 de noviembre, de la vivienda de Cataluña y los distintos Decretos de desarrollo —-206/1992, de 1 de septiembre, del Libro del Edificio y 158/1997, de 8 de julio-, La Ley 2/1999, de Medidas de Calidad de la Edificación (art. 13) y normativa de desarrollo - Decreto 349/1999, de 30 de diciembre y Orden de 17 de mayo de 2000 - la Orden Foral 1217/2000, de 30 de octubre (modificada por Orden 1106/2001 de 24 de septiembre) de Navarra; y el Decreto 80/2001, de 2 de noviembre y Orden de 14 de febrero de 2002 del Libro del Edificio de Murcia.

${ }^{41}$ Como establece el art. 6 una vez firmado el certificado final de obra por la Dirección facultativa, el constructor puede hacer entrega de la obra al promotor. Éste puede, rechazarla (siempre que la motive por escrito en el acta fijándose un nuevo plazo de entrega) o aceptarla con o sin reservas. Si no existen reservas se firma el acta y en el supuesto que se realicen reservas, las mismas deben quedar reflejadas en el acta — concretando cuáles son y los plazos de subsanación-. En
} 
que a partir de la fecha en que se suscriba la citada acta se comienzan a computar los plazos de responsabilidad y las garantías establecidos en la $\mathrm{LOE}^{42}$, también la inclusión del acta de recepción entre la documentación de obra resulta interesante por la información que proporciona y la documentación que incorpora, ya que en el acta se debe consignar: a) las partes que intervienen (necesariamente, deben figurar y firmar la citada acta el constructor y el promotor) b) la fecha del certificado final de obra (o fase completa o terminada) pero también el certificado final que se adjunta al acta, c) el coste final de la ejecución material de la obra y d) la declaración de recepción con o sin reservas y en el primer caso además el acta aneja de los defectos subsanados y aceptados, pues en este último supuesto los plazos de responsabilidad y garantías empiezan a computarse desde la fecha de esta última acta (art. 6 LOE).

El artículo 7 del mismo texto legal se refiere también a la obligación de consignar en la documentación de la obra ejecutada una relación identificativa de los agentes que han intervenido en el proceso de edificación. Esta obligación suscita algunas dudas, centradas, principalmente, en el detalle de la relación, es decir, si el mandato se cumple mediante la inclusión sólo de los sujetos que la Ley menciona o, por el contrario, es preciso indicar todos los que han intervenido efectivamente, tales como los subcontratistas, el jefe de obra, los profesionales que emiten informes o dictámenes - como geólogos- las personas físicas o jurídicas que dependen del Constructor o del Director, etc.. A mi entender, y teniendo en cuenta la finalidad de la existencia de la documentación, la relación debe comprender necesariamente a los sujetos que la Ley regula y les atribuye responsabilidad (promotor, constructor, proyectista y Dirección facultativa), pues no debe olvidarse que la citada documentación ${ }^{43}$.

Finalmente, la LOE exige que la documentación de la obra ejecutada se complete con las instrucciones de uso y mantenimiento del edificio y sus

\footnotetext{
este supuesto se recepciona parte de la obra (la que no tiene reserva) y el resto, una vez efectuada la subsanación, debe consignarse en un acta aparte.

${ }^{42}$ Se debe señalar que el propietario sólo tiene conocimiento de aquellos plazos cuando adquiere el inmueble, pues, con carácter previo, no existe obligación del promotor ni de ningún otro sujeto de dar a conocer esa información. Es decir, la citada documentación que conforma el libro del edificio sólo debe darse cuando el sujeto es propietario, no con carácter previo

${ }^{43}$ En todo caso es importante destacar que la relación que allí se realiza no puede ser constitutiva de responsabilidad. En primer lugar porque la inclusión de los sujetos no precisa necesariamente de su consentimiento, con lo cual pueden existir errores (voluntarios o involuntarios). En segundo y principal, porque la responsabilidad civil es personal e individualizada, tanto por actos u omisiones propios, como por actos u omisiones de personas por las que con arreglo a esta Ley se debe responder (art. 17.2 LOE)
} 
instalaciones. Por tanto, son dos los aspectos a tener en cuenta; el del edificio en sí y el de las instalaciones. Lo primero que hay que destacar en relación con ellos es qué documentación comprenden, quién debe facilitarla y a quién se debe entregar. En relación con el primer punto, se debe destacar que la indeterminación de la norma no permite hacer ninguna afirmación concreta sobre qué tipo de documentación se debe incluir. Por tanto, su concreción hay que buscarla en la normativa autonómica - caso de la Ley 2/1999, de la Calidad de la Edificación de la Comunidad de Madrid (art. 5.5) que exige que las instrucciones de uso formen parte del proyecto-, en la normativa específica de las instalaciones - caso de la Orden de 26 de octubre de 1999 en relación con la Infraestructura Común en telecomunicaciones - o, en cada caso, en lo que el Director de Obra considere, pues a este sujeto corresponde «...elaborar y suscribir la documentación de la obra ejecutada...». En el desarrollo de tal labor será ayudado por el Director de la ejecución de la obra (art. 13.2.f), por el constructor (art. 11.2.g) y por el o los suministradores de productos que deben «facilitar, cuando proceda, las instrucciones de uso y mantenimiento de los productos suministrados, así como las garantías de calidad correspondientes, para su inclusión en la documentación de la obra» (art. 15.2). En cualquier caso, es importante destacar que el promotor, como agente director de todo el proceso edificatorio tiene facultades para colaborar o completar la citada documentación.

Finalmente, la LOE precisa que el Libro del Edificio - del cual forma parte la Documentación de obra ejecutada-debe ser entregado a los adquirentes por el promotor junto con los otros documentos que sean exigibles por las Administraciones competentes (arts. 7 y 8.2.e) ${ }^{44}$, siendo de destacar las respectivas licencias, tales como la de primera ocupación o la de usos, necesarias, como es sabido, para poder contratar la prestación de los servicios de luz, agua, telecomunicaciones, energía eléctrica y otros con las compañías suministradoras.

\section{BIBLIOGRAFÍA CONSULTADA}

Carrasco Perea y otros, Comentarios a la Ley de Ordenación de la Edificación, edit. Aranzadi, 2000.

\footnotetext{
${ }^{44}$ Existe algún error en la redacción (se debería haber utilizado la conjunción «y» y no «0» en el art. 9.2.e). de los artículos, pero una interpretación conjunta de la Ley no permite a mi entender otra interpretación.
} 
INCIDENCIA DE LA LEY 38/1998, DE 5 DE NOVIEMBRE, DE ORDENACIÓN DE LA EDIFICACIÓN..

Carrasco Perea, A., Derecho de la construcción y la vivienda; edit. Dilex, S.L.; Madrid.

De los Mozos, J.L.; «La tecnificación del derecho de superficie», publicado en Estudios sobre el Derecho de los bienes; Edit. Montecorvo; Madrid, 1991.

De la Serna Bilbao, Manual de Derecho de la Edificación, editorial CEURA, 1999 y «Presentación de la Ley de Ordenación de la Edificación», La Ley, Avance mensual, noviembre de 1999, n. ${ }^{\circ} 10$.

Díez-Picazo, L. y Gullón, A., Sistema de Derecho Civil, Vol. III; Edit. Tecnos; Madrid, 1986.

González Pérez, J.; Comentarios a la Ley de Ordenación de la Edificación, Civitas, 2000.

García Macho, Comentarios a la Ley de Ordenación de la edificación: régimen jurídico y técnico, edit. COLEX, Madrid, 2000.

Parejo Alfonso, L. (Dir.), De la Serna Bilbao, M.N. (Coord.), Comentarios a la Ley 38/1999, de 11 de noviembre, de Ordenación de la Edificación, Editorial Tecnos, 2001.

Parejo Alfonso, L.; Garantía institucional y Comunidades autónomas; Ed. IEAL; Madrid, 1981, «La autonomía local en la Constitución» en Tratado de Derecho Municipal; Edit. Civitas; Madrid, 1988; pp. 17 y ss. y La potestad normativa de los entes locales, Edit. Marcial Pons; Madrid, 1998,

Porto Rey, Comentarios a la Ley de Ordenación de la Edificación, Montecorvo, 2000. 